\title{
AREÚSA: DE FERNANDO DE ROJAS A ANGELINA MUÑIZ-HUBERMAN
}

\author{
Jéromine François \\ Université de Liège \\ Jeromine.Francois@ulg.ac.be
}

\begin{abstract}
RESUMEN: La novela Areúsa en los conciertos (2002) de Angelina Muñiz-Huberman se construye a partir de una red de guiños intertextuales a La Celestina, obra clásica del panteón literario español. Este estudio examina la relevancia y las funciones de estos juegos intertextuales en el texto mexicano. Por una parte, las referencias celestinescas inician una crisis global de la protagonista epónima, que llega a cuestionar su identidad y su marco espacio-temporal. Esta problematización se interpreta en el marco de la poética del exilio de Angelina Muñiz. Por otra parte, con el fin de sobrepasar su estado de crisis, la Areúsa mexicana recupera ingredientes de la Areúsa medieval — su erotismo desenfrenado, su inconformidad social - para elaborar una reflexión contemporánea sobre la sexualidad femenina y las normas sociales que la restringen.
\end{abstract}

PALABRAS CLAVE: Areúsa, La Celestina, intertextualidad, crisis

\begin{abstract}
Angelina Muñiz-Huberman's novel Areúsa en los conciertos is constructed around a web of intertextual hints coming from La Celestina, a classic of the Spanish literature pantheon. The present essay analyses the importance and the roles played by these intertextual games in the Mexican text. On the one hand, the Celestinian references initiate the global crisis of the eponym character, who will question her own identity and her time-space period. This problematic is developed through Angela Muñiz's poetic of the exile. On the other hand, in order to overtake her state of crisis, the Mexican Areúsa recycles the ingredients of the medieval Areúsa-its insatiable eroticism, its social unconformity-in order to elaborate a contemporary reflection on female sexuality and on social rules which restrict it.
\end{abstract}

KEYWORDS: Areúsa, La Celestina, intertextuality, crisis

\section{Introducción}

La Celestina o Tragicomedia de Calisto y Melibea, de Fernando de Rojas, ${ }^{1}$ es una obra clásica del panteón literario español que ha conocido un éxito multisecular. Desde su publicación a finales del siglo $\mathrm{XV}$, este texto ha dado lugar a muchas continuaciones $\mathrm{y}$ adaptaciones que recrean de forma más o menos libre sus episodios y personajes. En este corpus amplio, una serie de textos movilizan el hipotexto clásico para cuestionar su tiempo.

\footnotetext{
${ }^{1}$ Por cuestiones de practicidad, designaré La Celestina como el texto de Rojas, sin entrar en los debates, todavía vigentes, acerca de la autoría del clásico español.
} 
En el marco de este estudio, me propongo examinar la relevancia y las funciones de la intertextualidad celestinesca en uno de estos textos, Areúsa en los conciertos, publicado en 2002 por la autora hispano-mexicana Angelina Muñiz-Huberman. En esta novela, veremos que las referencias celestinescas provocan una crisis ontológica por parte del personaje de Areúsa: la toma de conciencia de su nombre celestinesco causa una fragmentación de su identidad. De forma paralela, esta identidad problemática va a engendrar una reflexión sobre los contextos de crisis histórica del siglo XX —el holocausto, la guerra civil española y los exilios consecuentes - y sobre los contextos de represión de la sexualidad femenina.

\section{La Areúsa primigenia: señas de identidad}

En La Celestina de Rojas, Areúsa es una prostituta que pasa de mero personaje secundario a verdadera protagonista. En la Tragicomedia (1502), versión amplificada de la Comedia de Calisto y Melibea (1499), es su afán de venganza lo que provoca el accidente mortal de Calisto y, a raíz de este, el suicidio de Melibea. En el acto XV, en efecto, Areúsa planifica con Elicia vengarse de los amantes nobles, que ambas rameras juzgan responsables del fallecimiento de los criados, Sempronio y Pármeno, y de la alcahueta Celestina. En este proceso, Areúsa aparece como una maestra en el arte celestinesco de la persuasión, ya que manipula a Sosia, gracias a argumentos sexuales, para conseguir informaciones sobre los amantes. La joven ramera se jacta de su competencia: "otra arte es ésta que la de Celestina, aunque ella me tenía por boba porque me quería serlo" (Rojas, 2011: 306).

La figura de Areúsa ha interesado mucho a la crítica (Lacarra, 2005; Morros Mestres, 2010; Ramírez Santacruz, 2004), pues esta prostituta fascina, en La Celestina, por sus discursos, bastante modernos y virulentos, sobre la injusticia de las disparidades sociales. Incluso rechaza ferozmente el criterio genealógico de la aristocracia: a su juicio, la nobleza debe de ser una de actos y no de sangre: "las obras hacen linaje, que al fin todos somos hijos de Adán y Eva. Procure de ser cada uno bueno por sí, y no vaya a buscar en la nobleza de sus pasados la virtud" (Rojas, 2011: 208). Repite esta idea en el auto XVIII, cuando dice a Centurio que "no curemos de linaje ni hazañas viejas" (311). Más adelante en el acto IX, la llegada de Lucrecia engendra por parte de Areúsa un largo parlamento en contra de la vida de las criadas, en el que denuncia la desigualdad social, el maltrato de las sirvientas, la crueldad de las amas, y en el que reivindica su propia autonomía.

El personaje de Areúsa representa así una prostituta algo rebelde que afirma su individualismo, pregona su independencia y su derecho a utilizar su cuerpo a su voluntad. Areúsa es, en efecto, la única cortesana de La Celestina que trabaja de forma autónoma, y escapa así del control de una alcahueta o de un rufián.

\section{Una Areúsa mexicana del siglo xx: identidad intertextual y crisis}

Aunque se trata de un personaje muy importante de la Tragicomedia (Morros Mestres, 2010), la figura de Areúsa no se recrea con frecuencia en la celestinesca actual. Constituye una notable excepción la novela de Muñiz-Huberman, que desde el mismo título ofrece protagonismo a aquella prostituta. Areúsa en los conciertos cuenta la historia de una mujer joven que, después del fallecimiento de sus padres adoptivos, sale en busca de su madre 
biológica e intenta definirse una identidad al recorrer los lugares del globo que marcaron las distintas etapas de su existencia. Ahora bien, lo que desencadena este cuestionamiento existencial no es, hablando con propiedad, la pérdida de la familia adoptiva, sino más bien la necesidad global que siente el personaje de Areúsa de "repasar su historia para comprender antes de morirse" (Muñiz-Huberman, 2002: 17). ${ }^{2}$ Según la joven, el principio de su historia coincide sobre todo con la elección de su nombre: "Su nombre, ¿a quién se le ocurrió? A sus padres: no se sabe si por originalidad, ignorancia o profecía. En toda la historia nominativa, se conoce un solo antecedente: el de Fernando de Rojas al bautizar a una prostituta que trabajaba para la Celestina. Claro que si esto no se sabe, hasta puede parecer un nombre bello y bien sonante" (21-22).La Areúsa de finales del siglo XX se sume luego en la lectura de La Celestina para interrogar el significado de este nombre que comparte con una cortesana literaria de finales del siglo XV. El lector de Muñiz-Huberman que conoce la obra de Rojas percibe inmediatamente puntos en común entre las dos protagonistas, siendo ambas prendadas de libertad y erotismo (Cándano Fierro, 2011).

Esta problematización del nombre literario heredado va a engendrar una crisis de identidad por parte del personaje de Muñiz que decide por tanto auto-investigarse. Es a través de la retrospección que la Areúsa mexicana empieza tal introspección. El personaje del siglo $\mathrm{XX}$ busca en efecto su identidad vía una recuperación memorial de su pasado. Los viajes que conducen a Areúsa de un continente a otro a lo largo de la novela representan, ante todo, viajes temporales al hilo de los cuales la joven revive su historia personal: desde México, capital en la que vive al principio del texto, Areúsa llega a Filadelfia, ciudad de sus estudios universitarios y de sus primeros amoríos, para luego regresar a París, donde había pasado su infancia y donde conoce a su madre biológica. La búsqueda de sí misma, originada en la toma de conciencia de la intertextualidad de su nombre, se orienta por consiguiente hacia el pasado. El pasatiempo favorito de Areúsa consiste asimismo en dibujar imposibles árboles genealógicos (21): para concretar su presente, el personaje se ve obligado a re-explorar su pasado. La meta de Areúsa, a través de sus viajes intercontinentales, es "revisitar el pasado, reencontrarse con las personas y los lugares diferentes de su vida (su primer amor, su madre, sus amigos) para recuperar la memoria y, así, afianzar sus raíces en el presente y su identidad" (Pardes, citado por Walde, 2014: 161).

Esta exploración del pasado conduce a la Areúsa contemporánea a una obsesión por el tiempo que, como la identidad, huye a medida que se lo persigue: la joven "descubrió que el tiempo era un invento más como las otras arbitrariedades erótico-humanas" (22). La dificultad de aprehender el tiempo se reflejará rápidamente en la narración: el tiempo del relato es constantemente entrecortado por la irrupción de analepsis, y esta fragmentación también se proyecta en la protagonista, cuya identidad se corta en distintos estratos temporales. En cada nueva etapa de su vida, Areúsa es otra y es la razón por la cual la protagonista se siente acosada por la multiplicidad de su ser, además de debatirse entre estas diferentes versiones de sí misma y su versión literaria. La temporalidad del personaje de Muñiz se confunde rápidamente con la de su homónima celestinesca: “Areúsa no puede ir contra su siglo. El siglo del desencanto. Del enorme peso acumulado de duelos y quebrantos, pesadillas y formas de

\footnotetext{
${ }^{2}$ La edición que utilizo a lo largo de este trabajo es la de Alfaguara, 2002. Las citas que extraigo de dicha edición se indicarán en adelante solamente a través del número de página.
} 
hechicería. El siglo de su antigua antecesora o el actual que vive. ¿Cuál de las Areúsas es Areúsa? Areúsa quebrantada: esa soy yo" (201-202).

A fuerza de tanta fragmentación, el tiempo pierde paulatinamente, en el relato, su tripartición pasado-presente-futuro. Areúsa confunde las diferentes etapas de su vida, ya que "[a] fuerza de tanto exilio, Areúsa [...] ya no sab[e] la época en que viv[e]" (174), y la protagonista llega incluso a afirmar que "recordar es volver al presente" (76). Es interesante constatar, en la narración de acontecimientos que se desarrollan de forma simultánea, una alternancia constante de los tiempos del pasado y de los del presente. A partir de esta eliminación de los jalones temporales, el tiempo se hace cíclico, "Cíclico ciclismo. Reciclismo" (189). Es este carácter cíclico que, de cierta forma, es la única respuesta al nombre de Areúsa: cada identidad es la repetición de una identidad anterior y los personajes, "aunque modernos parecen, retornados son. Retornables también" (189). Este principio de repetición se aplica también a la literatura en general, condenada a la repetición: "La ficción no es sino la esterilidad y la unicidad, porque los libros se reproducen siempre igualitos. Así que el modelo a seguir es la reproducción literaria y adelante" (177).

Esta crisis paralela de la identidad y de la temporalidad, el personaje de MuñizHuberman la atribuye a su siglo, época de guerras, exilios y por tanto de fracturas: "en esta época que le había tocado vivir a Areúsa, luego de tanta guerra y bomba, lo único reconocible eran los fragmentos. Estaba acostumbrada a las sinécdoques: es decir, cada partecita de inmediato la remitía al gran, gran objeto" (149). La identidad fragmentada conduce así a que Areúsa reflexione sobre la dificultad de entender la historia del siglo XX, que aprehende como una sucesión de crisis que hacen eco a su propia crisis existencial.

Después de haber iniciado el cuestionamiento de su identidad a partir del nombre intertextual que le dio su madre antes de abandonarla, la Areúsa de Muñiz-Huberman sigue con su auto-investigación a través de una interrogación de las crisis del siglo XX. Cabe señalar que esta Areúsa inicia su búsqueda existencial a partir de los dos únicos indicios de su personalidad que le legó su madre: por una parte, este nombre de origen celestinesco; por otra parte, una ascendencia judía. Tal ascendencia es doble, ya que se debe tanto a Simone - la madre biológica que dio a luz a Areúsa después de ser violada y luego la abandonó- como a los padres adoptivos de la joven, judíos que murieron en un accidente automovilístico. Los orígenes semíticos de la protagonista se asocian, así, de entrada con la tragedia. Areúsa, la también judía, vive pues en un constante desarraigo. Según Salomé, amiga de la chica, la vida de Areúsa "ha sido un constante ir y venir. Es un producto de nuestro siglo y un producto de los constantes exilios. [...] su exilio empezó con la historia de Simone, su madre, perseguida e internada en un campo de concentración nazi” (128).

Es interesante señalar que Angelina Muñiz-Huberman hizo de la temática judaica una constante de su obra. ${ }^{3}$ En Areúsa en los conciertos, la temática del eterno exilio del judío se evoca a través de los grandes acontecimientos del siglo XX que supusieron importantes éxodos. Por un lado está la segunda guerra mundial, que además encarna quizá el trauma histórico más profundo de la comunidad judía. Por otro lado, Areúsa, durante sus proyecciones imaginarias en el pasado, fantasea con haber vivido la guerra civil española:

\footnotetext{
${ }^{3}$ A modo de ejemplos, se pueden mencionar Morada interior (1972), Tierra adentro (1977) o El sefardí romántico (2005).
} 
Las puertas de la muerte son algo que conoce de cerca y ya no le asustan. Ya no le parecen puertas que cierren o que abran: simplemente no son puertas. El tránsito no existe. La línea divisoria se ha borrado. Después de todo, ser sobreviviente de la guerra civil española no es despreciable. Aunque hayan pasado tantos años, las visiones siguen allí. O ella quiere que sigan allí. (56-57)

La recurrencia del motivo del exilio en la novela de Muñiz-Huberman es, de hecho, una característica de esta escritora de la generación hispano-mexicana. Dicha generación integra a los escritores españoles que, de pequeño o incluso poco tiempo después de nacer como es el caso de Muñiz-Huberman - se exiliaron con su familia a México a raíz de la guerra civil española. Por tanto, los autores de esta generación no vivieron realmente el exilio, sino que lo heredaron. De ahí que muchos de ellos cuestionen en sus obras su sentimiento de desarraigo y su derecho a sentirse exiliados (Pérez Aparicio, 2013; Sanz Villanueva, 1983; Walde Moheno y Reinosos, 2014). Se puede interpretar en este marco la presencia del exilio en Areúsa de los conciertos: al asociar el motivo del judío errante con la temática del exilio en tiempos de guerra civil o de guerra mundial, la escritora hispano-mexicana universaliza la noción de exilio y se otorga el derecho a tematizarlo.

Además, el motivo del judío errante permite que la autora conecte el tema del exilio, leitmotiv de su generación literaria, y su obsesión personal por su origen sefardí que descubrió en la adolescencia y que no deja de investigar a través de su narrativa (Bernárdez, 2013). Amén de convertirse al judaísmo, Muñiz-Huberman dedicó su carrera como académica de la UNAM al estudio de la cultura y literatura sefardíes. La universalización del motivo del judío errante culmina cuando Areúsa, durante un paseo por la Rambla barcelonesa, al final de la novela, se reconcilia con su historia trágica e incluso elogia el exilio que le es inherente: "ésta sería mi patria, piensa Areúsa, de poder elegir. Una patria encerrada en mí, por mí dibujada, por mí extendida. Porque patria-patria, no he tenido. De país en país, he amado el exilio" (Muñiz-Huberman, 2004: 167). Es de señalar que esta declaración de amor por el exilio presenta curiosas semejanzas con lo que expone la autora en su ensayo de 1993 titulado "La puerta del exilio", en el que define el exilio como su verdadera hogar.

En la última parte de sus peregrinaciones, Areúsa conoce a su madre biológica y la interroga sobre la elección de su nombre, cuyo referente literario constituye así, a la vez, el punto de partida y el término de su búsqueda de identidad. La revelación materna desconcierta a Areúsa. Su nombre representaría la antítesis de la perfección que iba a encarnar su hija:

te marqué con el nombre: el nombre sería el opuesto de lo que esperaba de ti. No tendrías ni un nombre simbólico, ni un nombre heredado, ni un bello nombre. Tendrías el nombre de un personaje olvidado, perdido en los bajos fondos, explotado y víctima, sin principios, sin esperanza, condenado, irredento. Fue así como te di el de Areúsa; una de las prostitutas que acompañan a la Celestina en su bajo mundo de maquinaciones y deslealtades. (144)

Areúsa se da entonces cuenta de que su identidad se ha construido, al contrario de lo que esperaba su madre, en adecuación con su nombre celestinesco. Ante la pérdida total de sus referencias familiares, espaciales y temporales le queda la posibilidad de aceptar y asumir la caracterización y el papel de su antecedente literario, cuyo erotismo comparte: a la pregunta “¿Qué hacer? ¿Caer de cuerpo en cuerpo? ¿Repetir su antigua historia y su antiguo nombre? ¿Encarnar el papel literario?” (125), contesta la constatación de que, desde el principio de su 
investigación, "las pisadas de la Areúsa de hoy intentan colocarse en las pisadas de la Areúsa de ayer" (78). Como explica Samblancat Miranda, esta aceptación final del nombre literario y de sus implicaciones presenta la literatura como "un sitio de reconocimiento íntimo para revivir y reinterpretar el pasado que continúa reciclándose y conservándose vigente" (2014: 121). Esta paz encontrada por el personaje a través de la interpretación de su nombre parece además reflejarse en una narración en la que los tiempos del presente empiezan poco a poco a prevalecer frente a los tiempos del pasado. La recuperación del pasado y el hallazgo de la identidad pasan así por una reapropiación del origen literario del nombre y por la aceptación de la herencia literaria.

\section{Aceptación de la identidad intertextual: la sexualidad como fuente de emancipación}

A medida que acepta su ascendencia literaria, el personaje epónimo de Areúsa en los conciertos sobrevalora cada vez más su erotismo, afición que precisamente tenía en común con su homónima celestinesca desde el principio de la novela. Es de notar que el personaje de La Celestina ha sido a veces analizado como "encarnación de la lujuria, la seducción, el erotismo" (Díaz Tena, 2012: 87) o "figura del placer" (Fernández, 1991: 52). Iniciada en las cosas eróticas por su madre, la Areúsa mexicana incluso llega a elaborar una teoría del amor carnal en un cuaderno que titula Florilegio de amantes, y en el que construye una tipología que diferencia el amor ovidiano, el freudiano, el sadiano, jungiano, aeróbico, etc. (97-98). Si el personaje mexicano hereda en buena parte esta obsesión por lo erótico de su modelo rojano, el motivo sexual conoce aquí sin duda un tratamiento hiperbólico. Desde las primeras páginas de la novela, se indica que "llegar al móvil del erotismo" (13) constituye el "gran sueño de la infancia que acompañaba a Areúsa" (13), que "ha sido creada por amor y para amor" (44). Asimismo, el personaje afirma haber "dedicado su vida a la colección de actos de amor" (24).

En su cuaderno, Areúsa desarrolla una reflexión constante sobre las representaciones sociales y artísticas del sexo, sobre todo femenino: “Areúsa se pregunta: ¿Qué les pasa a los desenfrenados? ¿Por qué en el centro de la pregunta está la prostitución? ¿Qué significa la pornografía? ¿Por qué temen tanto los hombres a las mujeres? ¿Por qué no puede ser natural la sexualidad? ¿Por qué los velos?” (15). Con este tipo de preguntas, Areúsa inicia un comentario sobre las relaciones problemáticas entre hombres y mujeres, así como una denuncia de las desigualdades de género y de las violencias sexuales, todavía vigentes en el siglo XX que le toca vivir. Después de leer la noticia de la muerte de una niña, "desangrada tras de una circuncisión de clítoris" (179), Areúsa observa así amargamente, "al fin: carne prescindible de mujer" (180).

Una especie de Don Juan femenino, el personaje de Areúsa creado por la autora hispano-mexicana "busca cuerpos" (124) porque "no halla satisfacción" (124). Considera el deleite sensual como una vía para acceder a otras realidades: “¿qué es el placer?, sino la extensión de una medida más allá de sí y hasta su ruptura" (124). Comparte esta visión casi mística de la sexualidad con el personaje de Salomé, doble de la Areúsa de Muñiz-Huberman (Pérez Aparicio, 2012), que se considera como encarnación de su famosa homónima bíblica. Como Areúsa, Salomé también está obsesionada por la experiencia carnal. Cuando cuenta su mito, interpreta su baile ante Herodes como un acto amoroso sensual (42). Desde entonces, ve una cabeza cortada cada vez que hace el amor y considera por tanto que, en la elaboración de 
su mito, "el arte de la sensualidad es indudable que fue primordial" (87). Salomé incluso comparte con Areúsa su vena literaria, ya que planea escribir una novela erótica (183).

En este contexto, la violación de la madre de Areúsa, judía internada en un campo de concentración nazi, entra en un singular efecto dominó. Es a raíz de esta violación que Simone abandona a su hija después de darle el nombre de Areúsa. Es a raíz de este abandono que Areúsa, sin orígenes conocidos a los que referirse, utiliza este nombre para buscar en el personaje de Rojas los ingredientes de su personalidad. Luego, cuando se entera de la suerte de su madre y de que es fruto de una violación, Areúsa decide erigir el acto carnal en eje de su identidad para, en cierta medida, hacerle burla al trauma de su madre y sobrepasarlo a la vez. Areúsa y Salomé integran luego la violación en sus disquisiciones teóricas - y pesimistassobre el género humano y su relación con lo carnal: “¿Qué hombre no ha violado? Parece que es su papel. Y su definición por antonomasia. Empiezo a creer que el hombre está completamente atado a su instinto y que sólo tiene uno. Da vueltas y vueltas en su círculo vicioso sin que pueda salirse. Violar, matar, destruir, despedazar, torturar. Comerse los unos a los otros. He ahí el lema" (176).

Cuando no es violenta, la sexualidad también se puede representar como una vía de auto-realización plena del ser. Este papel iniciático de la sensualidad se desarrolla en esta novela corta en la cual el sexo llega a presentarse como modo de conocimiento. Lo afirman los mismos personajes: "el deseo no es sino la más exacerbada forma de conocimiento" (112). La práctica sexual contribuye también a la realización del ser porque posibilita el desarrollo de su potencial artístico. Las relaciones carnales preconizadas por Areúsa favorecen las prácticas artísticas y permiten conectar al ser humano con el mundo estético, tanto literario como musical. En la novela de Muñiz-Huberman, la preocupación constante de Areúsa por lo erótico se vincula, así, de entrada con el mundo de los conciertos. Cuando asiste a una función de Wozzeck de Alban Berg, en el primer acto, el placer estético de Areúsa es tal que se confunde con una excitación erótica que la hace precipitarse hasta el camarín del director de orquesta para acostarse con él durante la pausa. Para Areúsa, el oído es en efecto "el órgano receptor por excelencia. El órgano de la sensualidad" (15).

Tal asociación entre experiencia erótica y experiencia artística continúa en el museo Kimbell, en el que Areúsa y su amiga Salomé se quedan pasmadas ante un cuadro que "ha podido reunir los ofrecimientos de la imaginación sexual” (27), gracias a la representación de una escena de alcahuetería. El museo es así alabado por las dos mujeres como lugar de encuentro por excelencia, "donde el desnudo es permitido y ha sido liberado de la sexualidad" (25).

Sin embargo, la asociación artístico-erótica que privilegia el personaje de Areúsa está en el ámbito de la música. En este "mundo de artefactos, de ilusiones" (63), "la única existencia es la de lo inatrapable: la melodía musical" (63). Es curiosa esta tendencia que tienen los personajes de esta novela a buscar esta realidad de lo inmaterial justamente a partir de la materialidad del cuerpo humano. El clímax musical lleva al clímax amoroso y viceversa. El director de orquesta incluso se pregunta: “¿cómo llegar al clímax musical sin el clímax del amor? ¿Cuántas veces no sintió su sexo enardecido en medio de un concierto sin poder aplacarlo? Ahora había aparecido Areúsa y era la forma que necesitaba para encontrar el exacto punto en que se producía el sonido deseado" (31). Areúsa asegura de este modo una mediación (sexual) entre la música y su intérprete. 
En las últimas páginas del relato, la perfección musical del concierto, otra vez un programa de Alban Berg, es tal que provoca un incendio en la sala. El fuego evoluciona, entre metáfora de la pasión e incendio real, y el ritmo de la música conduce a que Areúsa se suba al escenario y se entregue, cuerpo y alma, al arte. El aumento progresivo de la violencia del incendio termina con una apoteosis, casi orgásmica, al final de la cual se concluye la novela: "La sala de conciertos es un meteorito. La Gran Pasión ha sido ejecutada" (209).

La experiencia erótica que Areúsa desarrolla a partir de su antecedente literario contribuye a la definición de la identidad del ser individual, a su conexión con su entorno y a su acceso a conocimientos espirituales y artísticos. Ahora bien, la libertad sexual de la que hacen alarde los personajes les sirve de modelo para reivindicar una libertad general. A medida que desarrolla su teoría del amor, la Areúsa mexicana adopta como lema "nunca es nada de nadie" (97), y empieza a defender una filosofía de la autonomía absoluta, al igual que su homónima celestinesca.

Tal afán de libertad conduce a que el personaje de Areúsa se oponga conscientemente a los discursos y a las representaciones negativas de la sexualidad que vehicula la sociedad. Como explica en efecto Mario Muñoz, "si la sexualidad es una construcción social, quiere decir, entonces, que no es autónoma, pues depende de las representaciones y limitaciones del imaginario colectivo" (2011: 4). Reflexionar sobre la sexualidad lleva en efecto a que los personajes cuestionen las prohibiciones, los tabúes y las opresiones latentes que encierran dichas representaciones del sexo. Más allá del sencillo cuestionamiento, lo que propone la Areúsa de Muñiz-Huberman es el rechazo total de estos marcos de referencia moral: "resuena en el interior de Areúsa como el principio del dislocamiento de la moral. ¿Qué importa el matrimonio? ¿Qué importa un hijo? Lo que importa es el amar en sí: el acto: y no las reglas" (14). La voluntad subversiva de la protagonista es obvia: "la ruptura, hay que llevarla hasta el fondo. Si este es el siglo deshecho y contrahecho, rompamos todo, pluraliza Areúsa” (17). Al lado de este rechazo puro y duro, otra solución propuesta frente a la opresión de los códigos morales es el cuestionamiento de la jerarquía placer-pecado versus contención-virtud. De nuevo, la actitud de la Areúsa mexicana es extrema: "pecado es una palabra que no existe en el vocabulario de Areúsa" (14).

Conviene recalcar una última estrategia que utiliza la ficción considerada para superar las representaciones negativas que impiden el pleno desarrollo de la filosofía carnal reivindicada por la nueva Areúsa, emulando a la Areúsa de Rojas. Esta estrategia consiste en elaborar una nueva religio amoris, una forma de divinizar, ya no a la dama amada, sino el sexo. Destaca efectivamente en Areúsa en los conciertos una rehabilitación de los placeres carnales al presentarlos como una vía de acceso a lo divino: la Areúsa de Muñiz-Huberman eleva así el sexo al rango divino como "equivalente de la creación de Dios: en un acto de amor y en un acto de contracción pudo nacer el universo" (80).

$\mathrm{Al}$ asumir su componente erótico esencial, el personaje celestinesco en segundo grado vislumbra, más allá del desarrollo individual y de la emancipación colectiva, la posibilidad de un cambio total de paradigma. La subversión del antiguo orden, el cual se encarna simbólicamente en el encarcelamiento del deseo sensual, puede dar el paso a una nueva realidad, a un nuevo mundo. Esta nueva Edad de Oro se retrata como una etapa anterior a Babel; una etapa en la que el desafío de la humanidad no es la falta de comunicación lingüística, sino la incomunicación entre los sexos. Para resolver la incomprensión entre los 
géneros, la Areúsa de Muñiz-Huberman se vuelve, aunque solo teóricamente, hacia un hermafroditismo mítico:

Estoy hartamente cansada del género humano. [...] Ah, quisiera aspirar a algo único como la totalidad abarcadora de razón y pasión. Mejor dicho que no existiera tal división y que desconociéramos esas dos palabras como si pudiéramos fundir los dos sexos en uno y se nos acabara el problema. Colorín colorado. Porque con dos sexos en uno y sin razón-pasión sería el fin de la injusticia y del dolor. Todo se nos volcaría en egoamor y dejaría de existir el misterioso otro. Nada más seríamos unos y unos y unos. Es decir, daría lo mismo que lo mismo daría. Qué divertido fin de la dialéctica. (176)

La hechicería, temática sobresaliente de La Celestina primigenia, también se tematiza en el texto mexicano en relación con la femineidad, su seducción y su poder de transgresión que amenazan el marco de referencia masculino. En la novela de Angelina Muñiz-Huberman, la protagonista comenta al propósito, con el libro de Rojas en mano:

El mundo del amor y del encantamiento son el mismo: por eso el misterio de la unión entre lo prohibido y lo peligroso. Abigarrado mundo de hadas y brujas sin fronteras uno y otro. Confusión de la mujer-madre, la mujer-amor, la mujer-muerte. [...] Nota al margen de los procesos inquisitoriales contra las pobres mujeres llamadas brujas: éstas, sorprendidas, sólo por el tormento dieron el sí a los inventos y patrañas de los sesudos inquisidores y teólogos que fueron los que sacaron de sus poderosa inventiva aquelarres, vuelos nocturnos, pócimas y bálsamos, afrodisiacos, maleficios, engendros y patas de macho cabrío. (34-35)

Para "confirmar lo anterior" (35), Areúsa enseguida transcribe en un cuaderno la descripción del laboratorio de Celestina que hace Pármeno en el primer auto. En esta reescritura de la autora mexicana, el personaje celestinesco en segundo grado parte así de la búsqueda de su homónima literaria en la Tragicomedia para luego problematizar la relación perpetua, en la literatura celestinesca, entre magia, mujer y subversión: "El problema está en el terror que tiene el hombre a toda fuerza proveniente de la mujer. Si es de mujer es diabólico: para esto están las historias de las brujas. [...] (Claro, piensa Areúsa: las brujas y las prostitutas, inventos masculinos)" (27).

\section{Conclusiones}

Como vimos a lo largo de este trabajo, La Celestina juega un papel significativo en la trama elaborada por Angelina Muñiz-Huberman. La intertextualidad de su nombre conduce a la Areúsa mexicana a un cuestionamiento ontológico. Tal crisis de la identidad se proyecta enseguida en el marco espacio-temporal del personaje, que se hace fragmentario y desordenado, y engendra una reflexión sobre las crisis históricas de la época que le toca vivir, cinco siglos posterior a la época de su antecesora celestinesca. En fin, el apaciguamiento del personaje corresponde con la aceptación de su intertextualidad: la Areúsa mexicana decide asumir su herencia e incluso revivificarla a través del componente erótico. Esta Areúsa "en segundo grado" recupera la característica principal de su homónima literaria y exacerba su potencial transgresor para hacerse portavoz de la emancipación femenina. En este sentido, la protagonista de Muñiz-Huberman emula al personaje de Rojas y actualiza el alcance del afán de libertad que ya expresaba a principios del siglo XVI: "Por esto, madre, he querido más vivir 
en mi pequeña casa, esenta y señora, que no en sus ricos palacios, sojuzgada y cativa" (Rojas, 2011: 213).

Esta recreación de un personaje celestinesco se hace además meta-reflexiva en cuanto a las relaciones entre herencia y auto-construcción. Las interrogaciones existenciales de la protagonista y la problematización de su ser y de su época a partir de un nombre celestinesco configuran una búsqueda de sí mismo y de su contexto que bien podría simbolizar la función principal de la literatura: hacernos reflexionar sobre nuestra naturaleza y nuestro lugar en el mundo.

\section{Bibliografía}

Fuentes primarias

MUÑIZ-HUBERMAN, Angelina (2002): Areúsa en los conciertos. México, Alfaguara.

ROJAS, Fernando de, y antiguo autor (2011): La Celestina. Tragicomedia de Calisto y Melibea. Edición y estudio de Francisco J. Lobera, Guillermo Serés, Paloma Díaz-Mas, Carlos Mota, Iñigo Ruiz Arzalluz y Francisco Rico. Barcelona, GalaxBernia Gutenberg Círculo de Lectores, col. "Biblioteca Clásica de la Real Academia Española"

\section{Fuentes secundarias}

BERNÁRDEZ, Mariana: "En el centro el exilio. Entrevista con Angelina Muñiz”, La Jornada Semanal (12 de septiembre de 1993), http://medina502.com/bernardez/entrevistas/angelica_muniz.php, 12/06/2015.

CÁNDANO FIERRO, Graciela: "Unión, separación, contraposición: las dos Areúsas", Destiempos, 33 (2011), 98-101.

LACARRA, Maria Eugenia (2005): "Las pasiones de Areúsa y Melibea”. En Ottavio DI CAMILLO y John O’NEILL (eds.): La Celestina 1499-1999. Nueva York, Hispanic

MORROS MESTRES, Bienvenido: "Areúsa en La Celestina: de la Comedia a la Tragicomedia", Anuario de Estudios Medievales, XL/1 (2010), 355-385.

PARDES, Marcela (2014): "El motivo del viaje en Areúsa en los conciertos de Angelina Muñiz-Huberman". En Lilian con der WALDE MOHENO y Mariel REINOSO INGLISO (eds.): Homenaje a Angelina Muñiz-Huberman. México, Grupo Destiempos, 160-169.

PÉREZ APARICIO, Naarai: "La otredad femenina en Areúsa en los conciertos de Angelina Muñiz-Huberman”, Mitologías hoy, 6 (2012), 71-82.

PÉREZ APARICIO, Naaraí (2013): Transgresiones en la obra narrativa de Angelina MuñizHuberman, tesis doctoral, http://www.tdx.cat/handle/10803/120151, 18/06/2015.

RAMÍREZ SANTACRUZ, Francisco: "Individualismo a ultranza en La Celestina: Areúsa y Melibea", Graffylia, 4 (2004), 64-71.

SAMBLANCAT MIRANDA, Neus (2014): "La travesía de la vida o el cuento de nunca acabar en Las confidentes". En Lillian von der WALDE MOHENO y Mariel REINOSO INGLISO (eds.): Homenaje a Angelina Muñiz-Huberman. México, Grupo Destiempos, 103109.

SANZ VILLANUEVA, Santos: “Angelina Muñiz, novelista de la generación hispanomexicana”, Dicenda, 2 (1983), 135-144. 
(C) Jéromine François

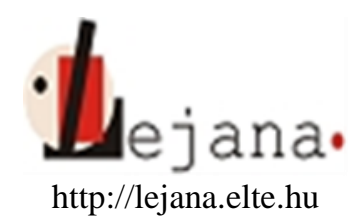

Universidad Eötvös Loránd, Departamento de Español, 1088 Budapest, Múzeum krt. 4/C

Recibido: 01 de junio de 2016

Aceptado: 07 de julio de 2016 